\title{
In Situ Evidence That Peripheral Insulin Resistance in Adolescents with Poorly Controlled Type 1 Diabetes Is Associated with Impaired Suppression of Lipolysis: A Microdialysis Study
}

\author{
RUBINA A. HEPTULLA, ALLISON STEWART, STEFFAN ENOCKSSON, FRAN RIFE, \\ TONY YONG-ZHAN MA, ROBERT S. SHERWIN, WILLIAM V. TAMBORLANE, AND \\ SONIA CAPRIO
}

Department of Pediatrics [R.A.H], Baylor College of Medicine, Clinical Care Center, Houston, TX 77030-2399, U.S.A.; and Department of Pediatrics[A.S., S.E., F.R., T Y-Z.M., R.S.S., W.V.T., S.C.], Internal Medicine and the General Clinical Research Center, Yale University School of Medicine, New Haven, CT 06520, U.S.A.

\begin{abstract}
This study was undertaken to examine whether insulin resistance in adolescents with poorly controlled type 1 diabetes mellitus (T1DM) is associated with the failure of insulin to suppress lipolysis in adipose and muscle tissues. Using microdialysis techniques, extracellular fluid concentrations of glycerol was measured in adipose and muscle tissue $3 \mathrm{~h}$ before and $3 \mathrm{~h}$ during a $0.8 \mathrm{mU} \cdot \mathrm{kg}^{-1} \cdot \mathrm{min}^{-1} \cdot$ euglycemic clamp. Ten adolescents with poorly controlled T1DM ( $\left.\mathrm{HbA}_{1 \mathrm{c}} 10.2 \pm 0.2 \%\right)$ were compared with six healthy lean adolescent control subjects. Despite similar increases in plasma insulin in both groups, diabetic subjects exhibited a $39 \%$ reduction in peripheral glucose uptake compared with controls $(p<0.05)$. In contrast, hepatic glucose production was fully suppressed by insulin in diabetic subjects. At the end of the clamp, extracellular glycerol concentrations were significantly elevated in subjects with diabetes (muscle: $85 \pm 7 \mu \mathrm{M}$ for diabetics and $51 \pm 8 \mu \mathrm{M}$ for controls,
\end{abstract}

\section{ABSTRACT}

$p<0.01$; adipose: $149 \pm 23 \mu \mathrm{M}$ for T1DM and $82 \pm 11 \mu \mathrm{M}$ for controls, $p<0.05$ ), indicating impaired in situ suppression of lipolysis in patients with diabetes. With all subjects considered, the rate of insulin-stimulated metabolism was inversely correlated to glycerol concentration in both adipose $(r=-0.63, p<$ $0.01)$ and muscle $(r=-0.63, p<0.01)$. Our data suggest that failure of insulin to inhibit lipolysis in muscle and adipose tissue contributes to the severe peripheral insulin resistance that characterizes poorly controlled T1DM during adolescence. (Pediatr Res 53: 830-835, 2003)

Abbreviations
T1DM, type 1 diabetes mellitus
ECF, extracellular fluid
HGP, hepatic glucose production

Type 1 diabetes mellitus (T1DM) in adolescents is a disease in which end organ resistance to insulin and deficiency of the hormone coexist (1). During normal puberty, responsiveness to insulin declines and this physiologic insulin resistance is exaggerated by poorly controlled diabetes (1-3). Compared with healthy lean preadolescents, healthy lean adolescents show a selective defect in insulin's ability to stimulate nonoxidative glucose disposal in peripheral (muscle and adipose) tissues; insulin-mediated increases in peripheral glucose oxidation are

Received June 27, 2002; accepted October 17, 2002.

Correspondence: Rubina A. Heptulla, M.D., Department of Pediatrics, Division of Endocrinology, Baylor College of Medicine, Clinical Care Center, Suite 1020, 6621 Fannin St. CC 1020, Houston, TX 77030-2399; e-mail: rheptulla@yahoo.com

Supported by National Institutes of Health Grants DK 20495, RR06022, and RR125 and Stephen I. Morse Pediatric Diabetes Research Fund. R.A.H. is a recipient of the Lawson Wilkins Clinical Scholar Award and the Baylor CHRC grant.

DOI: 10.1203/01.PDR.0000059552.08913.B7 unaffected by normal puberty $(4,5)$. In contrast, the exaggerated insulin resistance in adolescents with poorly controlled T1DM involves defects in insulin's ability to stimulate both oxidative and nonoxidative glucose metabolism (5).

An implication of the much debated glucose fatty-acid cycle (Randle cycle) is that increased FFA availability interferes with muscle glucose metabolism and contributes to the cause of many insulin-resistant states, including adolescence and T1DM $(6-8)$. Using the insulin clamp technique and indirect calorimetry, we have shown that severely insulin-resistant adolescents with poorly controlled T1DM fail to suppress circulating FFA levels or rates of fat oxidation in comparison with healthy adolescent controls in response to insulin levels similar to those achieved postprandially by healthy adolescents (5). The wholebody methods used in that study, however, did not allow us to distinguish the relative contributions of muscle and adipose 
tissues to alterations in responsiveness to insulin. Consequently, in the present study, microdialysis in muscle and adipose tissue were combined with the insulin clamp to examine insulin action, in situ, in the major peripheral sites of insulin action in adolescents with and without diabetes.

\section{METHODS}

\section{Subjects}

Sixteen subjects, 10 patients with T1DM and six controls without diabetes, were studied. All subjects were white. Table 1 describes the clinical features of patients who participated in the study. Subjects with T1DM were eligible for study when their disease duration was $>1 \mathrm{y}$, they had no symptoms or physical signs of autonomic neuropathy, they were receiving no medications other than insulin, their BMI was $<85 \%$ for age and sex, they had no acute illness, and their $\mathrm{HbA1C}$ was $\geq 9 \%$ (mean $10.0 \pm 0.2 \%$, normal $4.5-5.9 \%$ ). Lean healthy controls were siblings of patients with T1DM in the Yale Children's Hospital Diabetes Clinic whose BMI was $<85 \%$ for age and sex.

Adiposity was determined by calculating BMI and measurements of body fat composition using the dual-energy x-ray absorptiometry scan. The Human Investigation Committee of the Yale School of Medicine approved the study protocol, and informed written consent was obtained from all subjects and the parents of adolescent subjects.

\section{Microdialysis Technique}

The subjects were investigated in the supine position at $0800 \mathrm{~h}$ after an overnight fast. The microdialysis techniques for studies in s.c. adipose tissue have been described in detail (9). Briefly, a tubular polyamide dialysis membrane $(0.62 \times 30$ $\mathrm{mm}$, molecular weight cutoff $20 \mathrm{kD}$ ) is glued to the end of the outer cylinder of concentric double-lumen polyurethane tubing. The perfusate is continuously propelled by a microinfusion pump (CMA/100; CMA Medical, Stockholm, Sweden) and flows through the outer tubing into the space between the concentric cylinders to the distal end of the probe. The exchange of molecules between the extracellular fluid (ECF) and the perfusate occurs across the semipermeable dialysis membrane, after which the perfusate enters the inner cannula in a retrograde direction and is collected in timed fractions for later analysis of glycerol concentrations. In each subject, a microdialysis catheter (CMA/60; CMA/Microdialysis, Acton, MA,

Table 1. Clinical Characteristics

\begin{tabular}{lccc}
\hline & $\begin{array}{c}\text { T1DM } \\
\text { adolescents } \\
( \pm \text { SEM })\end{array}$ & $\begin{array}{c}\text { Normal control } \\
\text { adolescents } \\
( \pm \text { SEM })\end{array}$ & $p$ value \\
\hline$N$ & 10 & 6 & \\
Sex $(\mathrm{M} / \mathrm{F})$ & $7 \mathrm{M} / 3 \mathrm{~F}$ & $3 \mathrm{M} / 3 \mathrm{~F}$ & \\
Age $(\mathrm{y})$ & $16.2 \pm 0.6$ & $15.8 \pm 0.9$ & 0.74 \\
Height $(\mathrm{m})$ & $1.64 \pm 0.07$ & $1.62 \pm 0.03$ & 0.91 \\
Weight $(\mathrm{kg})$ & $66.8 \pm 3.2$ & $58.6 \pm 2.5$ & 0.1 \\
BMI $\left(\mathrm{kg} / \mathrm{m}^{2}\right)$ & $23.2 \pm 0.7$ & $22.2 \pm 0.8$ & 0.37 \\
HbA1C & $10.0 \pm 0.2$ & - & \\
$\%$ Body fat & $18.5 \pm 3.5$ & $20.7 \pm 3.6$ & 0.65 \\
\hline
\end{tabular}

U.S.A.) was placed in the medial portion of the left gastrocnemius muscle. Before insertion, the skin area corresponding to the contracted muscle was marked. Before the insertion, the skin was superficially anesthetized (EMLA; Astra, Sodertajee, Sweden) and local anesthetic was injected at the insertion site. At insertion, an assistant created a sharp skin fold with a tight grip. The point of insertion was the distal edge of this area, where the muscle tapers out to become the Achilles tendon. In this way, the catheter could be inserted proximally and parallel with the direction of muscle fibers, without any bending motion. Another catheter was placed in the periumbilical adipose tissue. This catheter was inserted horizontally in a medial direction from an insertion point $8 \mathrm{~cm}$ lateral to the umbilicus (10).

A 15-min flush was performed, followed by $3 \mathrm{~h}$ of equilibration to avoid a potential artifact caused by the insertion itself. The probe was connected to a microinfusion pump and was continuously perfused $(0.3 \mu \mathrm{L} / \mathrm{min})$ with artificial ECF $\left(135 \mathrm{mM} \mathrm{NaCl}, 3 \mathrm{mM} \mathrm{KCl}, 1 \mathrm{mM} \mathrm{MgCl} 2,1.2 \mathrm{mM} \mathrm{CaCl}_{2}, 300\right.$ $\mu \mathrm{M}$ ascorbate, and $2 \mathrm{mM}$ Na phosphate buffer adjusted to $\mathrm{pH}$ 7.4).

In each experiment, 60-min fractions of the outgoing dialysate were collected. The entire study lasted $6 \mathrm{~h}(3 \mathrm{~h}$ of equilibration period followed by $3 \mathrm{~h}$ of insulin infusion with variable rate glucose infusion). All dialysate tubes were weighed before and after collection, and volume was determined. Volumes between time points and between patients did not differ.

\section{Euglycemic-Hyperinsulinemic Clamp Procedure}

Subjects with diabetes were admitted to the Yale Children's Hospital Clinical Research Center on the evening before the clamp study. An i.v. catheter was inserted into an antecubital vein, and basal insulin was administered as a continuous i.v. infusion that was adjusted during the night based on plasma glucose measurements obtained every $30-60 \mathrm{~min}$. The plasma glucose concentrations did not fall below $4.0 \mathrm{mM}$ in any patients during the overnight period. The next morning, a second catheter was inserted retrograde into a vein of the contralateral hand for a blood sampling and kept patent by a saline infusion. This hand was placed in a heated box $\left(\sim 65^{\circ} \mathrm{C}\right)$ to arterialize venous blood (11). The subjects with diabetes and controls were studied in the morning after a 10 - to 12 -h overnight fast.

Three baseline blood samples were drawn at 10-min intervals at the end of the 3-h basal equilibration period. To quantify the basal rate of hepatic glucose production, we administered (3) glucose as a primed continuous infusion (2 $\mathrm{mg} \cdot \mathrm{m}^{-2} \cdot \mathrm{min}^{-1}$ ) starting at $-180 \mathrm{~min}$. At time 0 , the basal $\left[6,6-{ }^{2} \mathrm{H}_{2}\right]$ di-deuterated glucose infusion was discontinued and the insulin clamp was begun.

A two-step priming dose of insulin was administered (3.2 $\mathrm{mU} \cdot \mathrm{kg}^{-1} \cdot \mathrm{min}^{-1}$ followed by $1.6 \mathrm{mU} \cdot \mathrm{kg}^{-1} \cdot \mathrm{min}^{-1}$ each lasting $5 \mathrm{~min}$ ); this was followed by a continuous infusion of regular human insulin at $0.8 \mathrm{mU} \cdot \mathrm{kg}^{-1} \cdot \mathrm{min}^{-1}$ that lasted for 170 min (total of $3 \mathrm{~h}$ ). Plasma glucose was measured at the bedside at 5-min intervals (Beckman glucose analyzer; Beck- 
man, Fullerton, CA, U.S.A.) In both groups, plasma glucose was maintained at euglycemic levels $(\sim 5 \mathrm{mM})$ by a variable infusion of $20 \%$ dextrose. The $20 \%$ dextrose infusion was enriched to approximately $2.5 \%$ with (3) di-deuterated glucose to determine the rate of endogenous glucose production (if any) during the clamp procedure. Blood samples were taken at 10to 20 -min intervals for measurements of plasma insulin, glycerol, FFA (3), and $\left[6,6-{ }^{2} \mathrm{H}_{2}\right]$ di-deuterated glucose.

\section{Glucose Isotope Data}

Gas chromatography mass spectrometer analysis of enrichment of di-deuterated glucose in plasma and infusates was performed by the Yale stable isotope core facility by using penta-acetate derivative of glucose (12).

\section{Substrate and Hormone Measurements}

Plasma insulin was measured by a double-antibody RIA (Linco Research, St. Louis, MO, U.S.A.). In patients with T1DM, free insulin was determined by precipitating plasma samples at the bedside with polyethylene glycol, and all measurements were performed within 1 mo of each study. The recovery in healthy subjects after addition of PEG was $\sim 99 \%$

Plasma nonesterified fatty acids were assayed using a colorimetric method. Dialysate and plasma glycerol were measured in duplicate by an enzymatic fluorometric method using an automated multianalyzer (CMA/600; CMA/Microdialysis, Stockholm, Sweden). Levels of $\mathrm{HbA}_{1 \mathrm{C}}$ were measured by HPLC using Bio Rad (Hercules, CA, U.S.A.) equipment with a normal reference range of $4.5-5.9 \%$.

\section{Calculations}

Basal hepatic glucose production. Basal hepatic glucose production $=(f / s a) \times\left[\left(\right.\right.$ enrichment $^{\text {inf }} /$ enrichment $\left.\left.^{\text {plasma }}\right)-1\right]$, where $f$ is basal (3) glucose infusion rate ( $\mathrm{mg} / \mathrm{min}), s a$ is body surface area $\left(\mathrm{m}^{2}\right)$, and enrichment ${ }^{\text {inf }}$ is (3) glucose infusate enrichment (\%). The term "enrichment" refers to the fraction of isotope of glucose with respect to naturally occurring (native) glucose, expressed as a percentage.

Clamped hepatic glucose production. Clamped hepatic glucose production $=G I R \times\left[\left(\right.\right.$ enrichment $^{\text {inf }} /$ enrichment $\left.^{\text {plasma }}\right)-$ $1]$, where $G I R$ is mean glucose infusion rate $\left(\mathrm{mg} \cdot \mathrm{m}^{-2}\right.$. $\min ^{-1}$ ) during the clamp procedure (150-180 $\left.\mathrm{min}\right)$, enrichment $^{\text {inf }}$ is exogenous (3) glucose infusate enrichment (\%), and enrichment ${ }^{\text {plasma }}$ is steady-state clamped plasma (3) glucose enrichment (\%).

Clamped glucose disposal rate. Clamped glucose disposal rate $=$ clamped hepatic glucose production $+G I R$

\section{Gas Measurements and Calculations}

Respiratory gas exchange measurements. Respiratory gas exchange rates were measured by a computerized open circuit indirect calorimetry (Deltatrac, Sensor Medics) with a ventilated hood system, as previously described (13). Basal measurements $30 \mathrm{~min}$ before and $30 \mathrm{~min}$ at the end of euglycemic clamp were used for comparison. Oxidation rates for carbohydrate, fat, and protein before and during the clamp procedure were calculated from the measure $\mathrm{O}_{2}$ consumption, $\mathrm{CO}_{2}$ production, and urinary nitrogen excretion, as previously described (14).

Calculations. During the insulin clamp study, the amount of glucose infused to maintain euglycemia provided a means of determining insulin-stimulated glucose metabolism. The glucose infusion rate was calculated at 20-min intervals and corrected for deviations from target plasma glucose level, as previously described (15).

\section{Statistics}

All values are expressed as mean \pm SEM. Repeated measures analysis of covariance controlling for basal differences in glucose oxidation was performed with a single factor to compare the responses of the different groups over time. Dunnett's procedure for multiple comparisons was used post hoc to localize effects. Differences were considered significant at the 0.05 level. Unpaired $t$ tests were applied to compare differences in clinical characteristics and baseline measures between patients and controls. SPSS (version 10.0) was used for statistical analysis.

\section{RESULTS}

Basal state. As shown in Table 2, the overnight insulin infusion normalized basal plasma insulin levels in patients with T1DM compared with controls. Basal plasma substrate concentrations and rates of glucose and fat oxidation also did not differ significantly between the two groups. In the subjects with diabetes, stable plasma enrichments of di-deuterated glucose were achieved at the end of the baseline equilibration period (i.e. $3.12 \pm 0.5 \%$ at $-30 \mathrm{~min}$ versus $3.17 \pm 0.5 \%$ at $0 \mathrm{~min}$ ). In these subjects, basal hepatic glucose production averaged 88 $\pm 9 \mathrm{mg} \cdot \mathrm{m}^{-2} \cdot \mathrm{min}^{-1}$. Because of mishandling of the blood samples in three of the six controls, the isotopic enrichment data were not analyzed in this group.

Responses to insulin. During the euglycemic insulin clamp, plasma insulin levels were raised to the same steady-state plateau ( $272 \pm 15$ for T1DM versus $294 \pm 21 \mathrm{pM}$; NS), and plasma glucose was maintained at $\sim 5 \mathrm{mM}$ throughout the study in the two groups. Despite similar increments in plasma insulin, the metabolic responses to insulin differed sharply in the two study groups.

Glucose metabolism. As shown in Fig. 1, the overall rate of insulin-stimulated glucose metabolism was significantly re-

Table 2. Baseline insulin, substrates, and rates of substrate oxidation in the two groups

\begin{tabular}{cccc}
\hline & $\begin{array}{c}\text { T1DM } \\
( \pm \text { SEM })\end{array}$ & $\begin{array}{c}\text { Normal controls } \\
( \pm \text { SEM })\end{array}$ & $p$ value \\
\hline Insulin and substrates & & & \\
$\quad$ Plasma insulin $(\mathrm{pM})$ & $93 \pm 11$ & $86 \pm 9$ & 0.54 \\
Plasma glucose $(\mathrm{mM})$ & $5.95 \pm 0.3$ & $4.55 \pm 0.13$ & 0.11 \\
Plasma FFA $(\mu \mathrm{M})$ & $500 \pm 73$ & $663 \pm 129$ & 0.25 \\
$\quad$ Plasma glycerol $(\mu \mathrm{M})$ & $38 \pm 3$ & $41 \pm 5$ & 0.12 \\
Substrate oxidation rates & & & \\
$\quad \begin{array}{l}\text { Glucose oxidation } \\
\mathrm{mg} \cdot \mathrm{m}^{-2} \cdot \mathrm{min}^{-1}\end{array}$ & $33 \pm 4$ & $44 \pm 5$ & 0.06 \\
Fat oxidation & $53 \pm 4$ & $40 \pm 5$ & 0.09 \\
$\quad \mathrm{mg} \cdot \mathrm{m}^{-2} \cdot \mathrm{min}^{-1}$ & & & \\
\hline
\end{tabular}




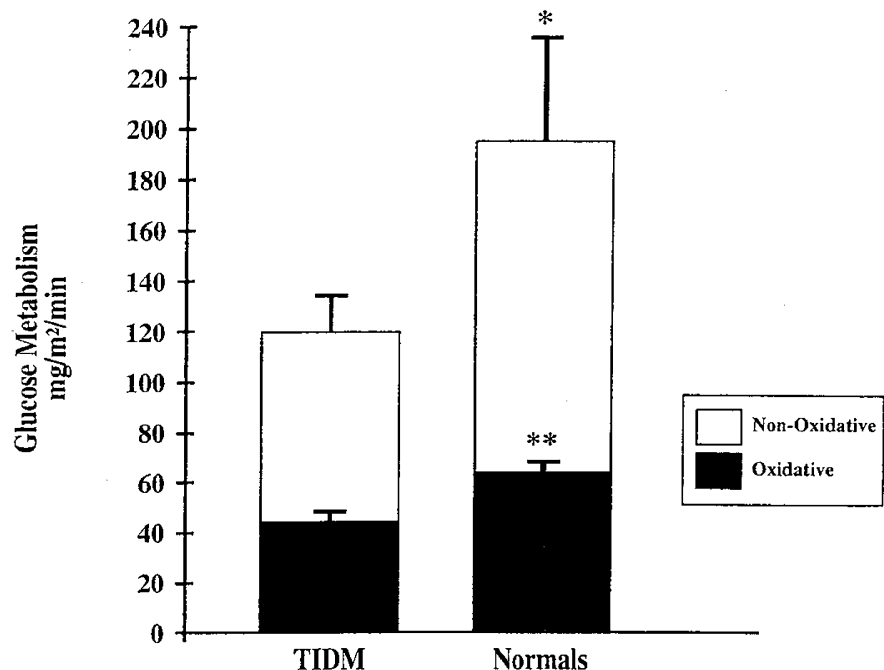

Figure 1. Each bar represents total body glucose disposal in controls and in poorly controlled T1DM during euglycemic-hyperinsulinemic clamp studies. Open segments denote rate of insulin-stimulated glucose oxidation, and closed segments denote rate of nonoxidative glucose metabolism. The asterisk denotes significance of difference for adolescents with diabetes $v s$ the control group. Data are expressed as mean and SEM $\left({ }^{*} p<0.05,{ }^{* *} p<0.01\right)$

duced in adolescents with poorly controlled T1DM compared with controls $\left(120 \pm 16\right.$ versus $196 \pm 39 \mathrm{mg} \cdot \mathrm{m}^{-2} \cdot \mathrm{min}^{-1}$; $p<0.05)$ as a result of reduction in both oxidative $(76 \pm 4 \mathrm{mg}$ $\cdot \mathrm{m}^{-2} \cdot \mathrm{min}^{-1}$ for T1DM versus $132 \pm 15 \mathrm{mg} \cdot \mathrm{m}^{-2} \cdot \mathrm{min}^{-1}$ for controls; $p<0.05)$ and nonoxidative glucose metabolism $\left(44 \pm 5 \mathrm{mg} \cdot \mathrm{m}^{-2} \cdot \mathrm{min}^{-1}\right.$ versus $63 \pm 5 \mathrm{mg} \cdot \mathrm{m}^{-2} \cdot \mathrm{min}^{-1}$; $p<0.01)$. Of note, hepatic glucose production was completely suppressed during the insulin clamp in the patients with diabetes.

Fat metabolism. The effect of poorly controlled diabetes on insulin-induced suppression of fat metabolism is shown in Fig. 2. In nondiabetic controls, the rate of fat oxidation fell by $45 \pm$ $4 \%$ during the insulin infusion versus only $20 \pm 2 \%$ in patients with T1DM $(p<0.002)$. Similarly, the percentage fall in plasma FFA and plasma glycerol levels was nearly 2-fold

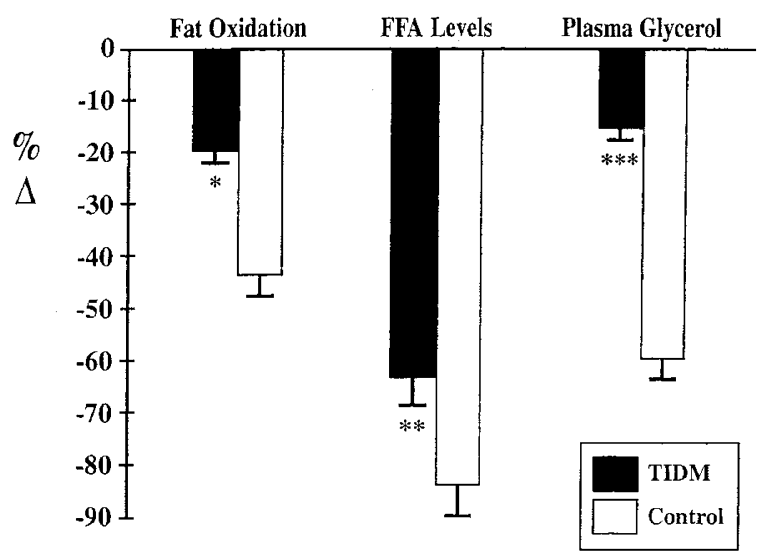

Figure 2. Insulin-induced changes in fat metabolism shown as percentage change from baseline ( $\square$, patients with T1DM; $\square$, controls). The asterisk denotes significance of difference for adolescents with diabetes $v s$ the control group. Data are expressed as mean and SEM $\left({ }^{*} p<0.002, * * p<0.01, * * * p\right.$ $<0.05)$. greater in subjects without than in subjects with diabetes $(p<$ 0.01 and $p<0.05$, respectively).

Extracellular glycerol concentrations in adipose and muscle by microdialysis. As shown in Figure 3A, basal concentrations of glycerol present in adipose microdialysate were similar in both the T1DM group $(239 \pm 25 \mu \mathrm{M})$ and the control group $(241 \pm 35 \mu \mathrm{M})$. However, insulin-induced suppression of interstitial glycerol levels was attenuated during the clamp in the patients with diabetes. During the second and third hours, glycerol concentration in adipose microdialysate were significantly higher in the T1DM group compared with the control group [149 $\pm 19 \mu \mathrm{M}$ for T1DM versus $85 \pm 7 \mu \mathrm{M}$ for controls during the second hour $(p<0.03)$ and $149 \pm 23 \mu \mathrm{M}$ for T1DM versus $82 \pm 11 \mu \mathrm{M}$ for controls during the third hour $(p=0.05)]$, indicating impaired suppression of lipolysis in patients with T1DM.

A similar pattern of responses was observed in muscle tissue as shown in Figure 3B. Basal muscle glycerol concentrations in microdialysate were similar in the T1DM group $(131 \pm 11$ $\mu \mathrm{M})$ and the normal control group $(141 \pm 10 \mu \mathrm{M})$. Overall, glycerol was much higher in T1DM compared with the control $(p<0.01)$, and this was seen by the third hour of the clamp

A.

Adipose Glycerol
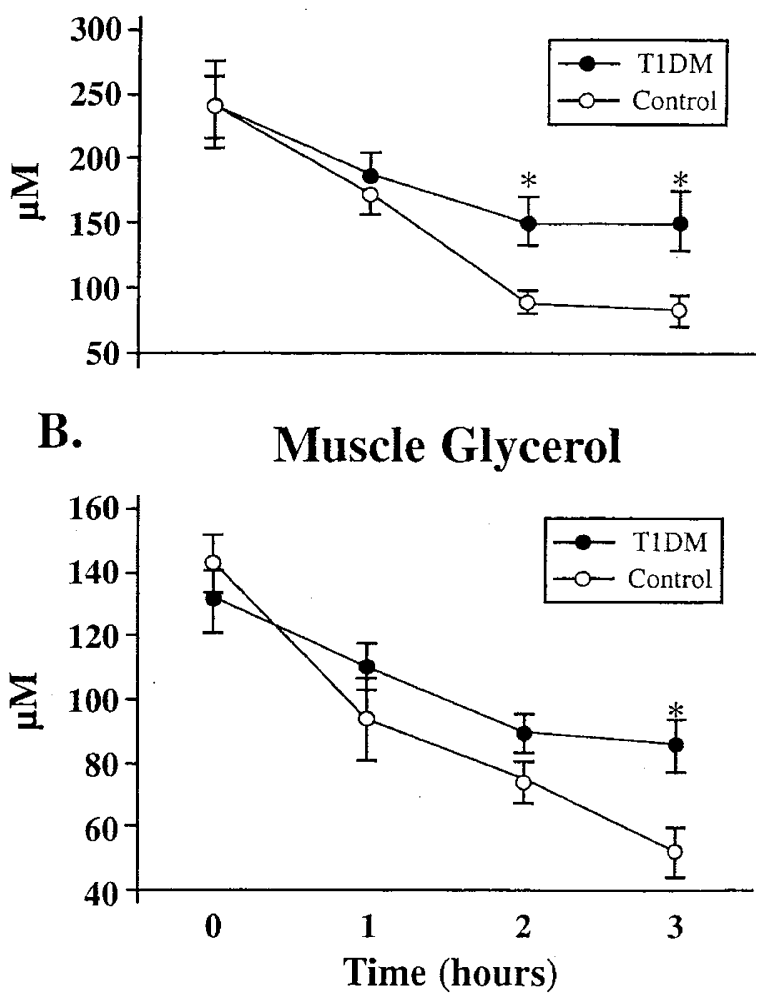

Figure 3. $A$, Absolute concentration of glycerol in ECF adipose microdialysate during the 3-h course of the glucose clamp procedure. $\bigcirc$, patients with T1DM; $\boldsymbol{\bullet}$, controls. The asterisk denotes significance of difference for adolescents with diabetes $v s$ the control group. Data are expressed as mean and SEM $(* p<0.05) B$, Absolute concentration of glycerol in ECF muscle microdialysate during the $3-\mathrm{h}$ course of the glucose clamp procedure. $\bigcirc$, patients with T1DM; , controls. The asterisk denotes significance of difference for adolescents with diabetes $v s$ the control group. Data are expressed as mean and SEM $\left({ }^{*} p<0.01\right)$. 
procedure; the T1DM group had a significantly higher muscle glycerol concentration in microdialysate when compared with the control group ( $85 \pm 7 \mu \mathrm{M}$ for the T1DM group versus 51 $\pm 8 \mu \mathrm{M}$ for the control group; $p<0.01$ ). Indeed, when the data are expressed as the percentage of suppression of glycerol from baseline, the suppression in ECF glycerol was significantly lower in the T1DM by the second hour $(30 \pm 4 \%$ for T1DM versus $48 \pm 3 \%$ for controls; $p<0.01)$ as well as at the third hour ( $34 \pm 4 \%$ for TIDM versus $64 \pm 5 \%$ for controls; $p<0.0001)$

With all subjects considered, an inverse relationship was observed between insulin-stimulated glucose metabolism and the concentration of glycerol in the ECF of adipose $(r=$ $-0.63, p<0.05)$ and muscle tissues $(r=-0.63, p<0.05)$ at the end of the clamp period (Fig. 4). A similar inverse correlation was observed between plasma glycerol levels and insulin-stimulated glucose metabolism $(r=-0.7, p<0.002)$ at the end of the clamp. These correlations persisted even when the subjects with T1DM and controls were considered separately. In T1DM, insulin-stimulated glucose metabolism and plasma glycerol, muscle glycerol, and adipose glycerol showed the following correlations separately: $r=-0.67, p<0.03, r$ $=-0.44, p<0.1, r=-0.61, p<0.05$. Although we had a small number of controls and two outliers within that group, the correlations between insulin-stimulated glucose metabolism and muscle and adipose glycerol persisted $(r=-0.61, p$ $<0.05, r=-0.63, p<0.05$ )

\section{DISCUSSION}

The hormonal changes of normal puberty cause a transient physiologic state of insulin resistance. This insulin resistance is markedly exaggerated in adolescents with poorly controlled diabetes, leading to defects in both the plasma glucose and lipid-lowering effects of insulin (16). In the present study, we combined microdialysis, stable isotopes dilution techniques, and indirect calorimetry with the euglycemic-hyperinsulinemic clamp to extend previous investigations regarding abnormalities in glucose and lipid metabolism during puberty in T1DM. The impairment in insulin's ability to stimulate overall rates of glucose metabolism in T1DM versus control subjects in this study is similar to that observed in previous studies using the insulin clamp procedure (1). Moreover, as originally described by Caprio et al. (5), this defect in insulin-stimulated glucose metabolism was due to a reduction in both oxidative and nonoxidative glucose disposal.

Decreased responsiveness to insulin in T1DM versus control (subjects without diabetes) adolescents was observed even through the overnight basal insulin infusion normalized fasting plasma insulin and glucose levels. Our data suggest that the overnight insulin infusion also normalized basal rates of hepatic glucose production. Using the same deuterated glucose tracer methods, we have previously shown that basal hepatic glucose production averages approximately $100 \mathrm{mg} \cdot \mathrm{m}^{-2}$. $\min ^{-1}$ in healthy lean adolescents, a value that is similar to that in the adolescents with T1DM in this study (17). Our previous study in nondiabetic adolescents also demonstrated that hepatic glucose production was completely suppressed during a 1.0 $\mathrm{mU} \cdot \mathrm{kg}^{-1} \cdot \mathrm{min}^{-1}$ insulin clamp, but the effect of puberty and poorly controlled T1DM on the liver's responsiveness to insulin had not been previously examined (17). Thus, it is noteworthy that the adolescents with T1DM in this study showed the same complete suppression of hepatic glucose production during the insulin clamp even though we used a slightly lower dose of insulin (i.e. $0.8 \mathrm{mU} \cdot \mathrm{kg}^{-1} \cdot \mathrm{min}^{-1}$ ) than used in the previous study of nondiabetic adolescents. Consequently, the observed defect in overall rates of insulin-stimulated glucose metabolism in adolescents with poorly controlled T1DM seems to be fully accounted for by impaired stimulation of peripheral glucose uptake rather than by hepatic resistance to insulin.

Our patients with T1DM also demonstrated a reduction in insulin's ability to suppress fat oxidation and to lower plasma levels of FFA and glycerol. Although some of these effects of poorly controlled T1DM on lipid turnover have been observed previously $(8,18-20)$, interpretation of such findings was limited because net changes in circulating lipid concentrations seemed to be insensitive surrogate markers for rates of lipolysis in peripheral tissues. Other studies have suggested that the failure of insulin to suppress lipolysis is a cause rather than a result of insulin resistance in diabetes, leading to increased availability of FFA for fat oxidation $(5,21)$ and decreased peripheral glucose utilization. For example, Boden et al. (6) infused lipids into healthy subjects and found an increase in fat oxidation and a decrease in peripheral glucose uptake. Similarly, preliminary results of nuclear magnetic resonance spectroscopy in lean and obese nondiabetic adolescents indicate
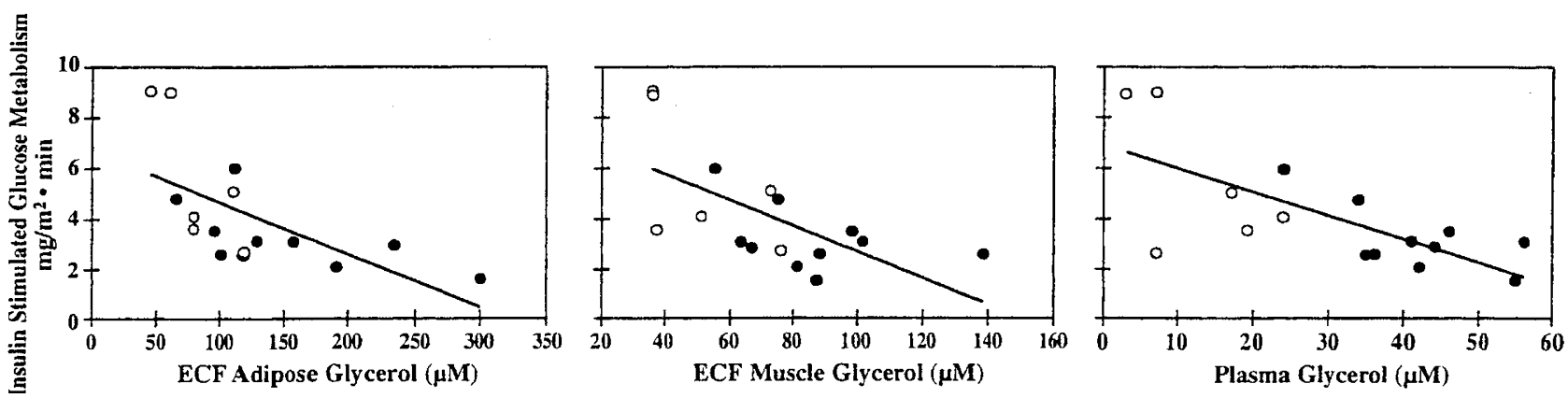

Figure 4. Correlations between adipose ECF $(r=0.63, p<0.01)$, muscle ECF $(r=0.63, p<0.01)$, and plasma glycerol $(r=-0.7, p<0.002) v s$ insulin-stimulated glucose metabolism at the end of 3-h glucose clamp procedure. $\bullet$, patients with T1DM; $\bigcirc$, controls. 
that insulin sensitivity is inversely related to the amount of intra- and intermyocellular fat (22).

In the current study, we used microdialysis techniques to address this question directly in peripheral target tissues of interest. Our data suggest that the suppressive effects of insulin on lipolysis within muscle and adipose tissue are substantially reduced in the T1DM compared with the normal control group, as indicated by the impaired ability of insulin to suppress ECF glycerol concentrations in the subjects with diabetes versus the control subjects. Moreover, when all subjects were considered, the absolute concentration of ECF glycerol in muscle and adipose tissue was inversely correlated with the rate of peripheral glucose uptake. The failure of insulin to suppress lipolysis in muscle is particularly important, because this is the primary site of insulin-stimulated glucose uptake.

Differences in insulin-induced changes in peripheral blood flow may have influenced microdialysis results. Namely, the greater fall in ECF glycerol concentrations in nondiabetic subjects could have been due, in part, to a greater increase in blood flow leading to more rapid washout of glycerol from the interstitial space. In the absence of a measure of blood flow in this study, we cannot be certain to what degree blood flow changes may have influenced dialysate glycerol during insulin infusion (23). However, if lower interstitial levels of glycerol occurred predominantly through an increase in blood flow rather than through suppressed lipolysis, then one would expect an increase rather than a decrease in circulating glycerol concentrations. It is also noteworthy that the responses in muscle tissue were similar to those in fat tissue (24). Studies have shown that insulin has little or no effect on local blood flow while lowering interstitial glycerol by $\sim 50 \%$ (25). In addition, because of the inability of fat tissue to reuse glycerol after hydrolysis of triglycerides and because there is minimal uptake of glycerol in muscle tissue after lipolysis, changes in ECF concentrations of glycerol in these tissues are primarily affected by alterations in the rate of lipolysis $(26,27)$.

\section{CONCLUSION}

In summary, the results of this study indicate that the severe insulin resistance that characterizes T1DM during adolescence is primarily related to defects in insulin-stimulated peripheral glucose uptake and, for the most part, spares the liver. Poorly controlled T1DM also adversely affects insulin's ability to lower circulating FFA and glycerol levels and to suppress lipolysis in adipose and muscle tissue. Although association does not prove causation, the reciprocal relationship between overall rates of glucose uptake and ECF and plasma glycerol concentrations are consistent with the hypothesis that failure of insulin to suppress lipolysis in peripheral tissue may play a key role in the insulin resistance of poorly controlled diabetes.

\section{REFERENCES}

1. Amiel SA, Sherwin RS, Simonson DC, Lauritano AA, Tamborlane WV 1986 Impaired insulin action in puberty. A contributing factor to poor glycemic control in adolescents with diabetes. N Engl J Med 315:215-219

2. Arslanian S, Nixon PA, Becker D, Drash AL 1990 Impact of physical fitness and glycemic control on in vivo insulin action in adolescents with IDDM. Diabetes Care 13:9-15

3. Arslanian S, Heil BV, Kalhan SC 1993 Hepatic insulin action in adolescents with insulin-dependent diabetes mellitus: relationship with long-term glycemic control. Metabolism 42:283-290

4. Arslanian SA, Kalhan SC 1994 Correlations between fatty acid and glucose metabolism. Potential explanation of insulin resistance of puberty. Diabetes 43:908-914

5. Caprio S, Cline G, Boulware S, Permanente C, Shulman GI, Sherwin RS, Tamborlane WV 1994 Effects of puberty and diabetes on metabolism of insulin-sensitive fuels. Am J Physiol 266:E885-E891

6. Boden G, Chen X, Ruiz J, White JV, Rossetti L 1994 Mechanisms of fatty acidinduced inhibition of glucose uptake. J Clin Invest 93:2438-2446

7. Kelley DE, Mokan M, Simoneau JA, Mandarino LJ 1993 Interaction between glucose and free fatty acid metabolism in human skeletal muscle. J Clin Invest 92:91-98

8. Roden M, Price TB, Perseghin G, Petersen KF, Rothman DL, Cline GW, Shulman GI 1996 Mechanism of free fatty acid-induced insulin resistance in humans. J Clin Invest 97:2859-2865

9. Arner P, Bulow J 1993 Assessment of adipose tissue metabolism in man: comparison of Fick and microdialysis techniques. Clin Sci 85:247-256

10. Arner P, Bolinder J, Eliasson A, Lundin A, Ungerstedt U 1988 Microdialysis of adipose tissue and blood for in vivo lipolysis studies. Am J Physiol 255:E737-E742

11. McGuire EA, Helderman JH, Tobin JD, Andres R, Berman M 1976 Effects of arterial versus venous sampling on analysis of glucose kinetics in man. J Appl Physiol 41:565-573

12. Royle GT, Wolfe RR, Burke JF 1983 The measurement of glucose turnover and oxidation using radioactive and stable isotopes. J Surg Res 34:187-193

13. Caprio S, Gelfand RA, Tamborlane WV, Sherwin RS 1989 Oxidative fuel metabolism during mild hypoglycemia: critical role of free fatty acids. Am J Physiol 256:E413-E419

14. Frayn KN 1983 Calculation of substrate oxidation rates in vivo from gaseous exchange. J Appl Physiol 55:628-634

15. DeFronzo RA, Tobin JD, Andres R 1979 Glucose clamp technique: a method for quantifying insulin secretion and resistance. Am J Physiol 237:E214-E223

16. Moran A, Jacobs DR Jr, Steinberger J, Hong CP, Prineas R, Luepker R, Sinaiko AR 1999 Insulin resistance during puberty: results from clamp studies in 357 children. Diabetes 48:2039-2044

17. Amiel SA, Caprio S, Sherwin RS, Plewe G, Haymond MW, Tamborlane WV 1991 Insulin resistance of puberty: a defect restricted to peripheral glucose metabolism. J Clin Endocrinol Metab 72:277-282

18. Arner P, Engfeldt P, Ostman J 1980 Blood glucose control and lipolysis in diabetes mellitus. Acta Med Scand 208:297-299

19. Roden M, Stingl H, Chandramouli V, Schumann WC, Hofer A, Landau BR, Nowotny P, Waldhausl W, Shulman GI 2000 Effects of free fatty acid elevation on postabsorptive endogenous glucose production and gluconeogenesis in humans. Diabetes 49:701-707

20. Dresner A, Laurent D, Marcucci M, Griffin ME, Dufour S, Cline GW, Slezak LA, Andersen DK, Hundal RS, Rothman DL, Petersen KF, Shulman GI 1999 Effects of free fatty acids on glucose transport and IRS-1-associated phosphatidylinositol 3-kinase activity. J Clin Invest 103:253-259

21. Cline GW, Magnusson I, Rothman DL, Petersen KF, Laurent D, Shulman GI 1997 Mechanism of impaired insulin-stimulated muscle glucose metabolism in subjects with insulin-dependent diabetes mellitus. J Clin Invest 99:2219-2224

22. Sinha R, Dufour S, Petersen KF, LeBon V, Enoksson S, Ma Y-Z, Savoye M, Rothman DL, Shulman GI, Caprio S 2002 Assessment of skeletal muscle triglyceride content by $1 \mathrm{H}$ nuclear magnetic resonance spectroscopy in lean and obese adolescents: relationships to insulin sensitivity, total body fat, and central adiposity. Diabetes 51:1022-1027

23. Hickner RC, Rosdahl H, Borg I, Ungerstedt U, Jorfeldt L, Henriksson J 1991 Ethanol may be used with the microdialysis technique to monitor blood flow changes in skeletal muscle: dialysate glucose concentration is blood-flow-dependent. Acta Physiol Scand 143:355-356

24. Maggs DG, Jacob R, Rife F, Lange R, Leone P, During MJ, Tamborlane WV, Sherwin RS 1995 Interstitial fluid concentrations of glycerol, glucose, and amino acids in human quadricep muscle and adipose tissue. Evidence for significant lipolysis in skeletal muscle. J Clin Invest 96:370-377

25. Johansson U, Arner P, Bolinder J, Hagstrom-Toft E, Ungerstedt U, Eriksson LS 1993 Influence of insulin on glucose metabolism and lipolysis in adipose tissue in situ in patients with liver cirrhosis. Eur J Clin Invest 23:837-844

26. Coppack SW, Persson M, Judd RL, Miles JM 1999 Glycerol and nonesterified fatty acid metabolism in human muscle and adipose tissue in vivo. Am J Physiol 276:E233-E240

27. Frayn KN, Coppack SW, Humphreys SM 1991 Glycerol and lactate uptake in human forearm. Metabolism 40:1317-1319 